\title{
Thermo-emf anisotropy and thermoefficiency parameter of the elastically deformed germanium and silicon with different doping levels
}

\author{
Institute for Nuclear Research of the NAS of Ukraine, Kyiv, Ukraine, gaydar@ kinr.kiev.ua
}

\begin{abstract}
The thermo-emf anisotropy $\Delta \alpha$ and the thermoefficiency parameter $Z_{a}$ are the most important characteristics that determine the suitability of thermoelectrically anisotropic materials for their practical use. The first of these characteristics determines the voltage generated by the anisotropic thermoelement, and the second one determines its efficiency coefficient. In this work, the features of changes in the thermo-emf anisotropy and the thermoefficiency parameter of the elastically deformed germanium and silicon crystals at $85 \mathrm{~K}$ depending on their doping level were investigated. It was revealed that in the case of a low doping level, the thermo-emf anisotropy of the deformed $n$-Si crystals exceeds $\Delta \alpha$ of $n$-Ge crystals more than 4 times. It was shown that a rapid decrease in $\Delta \alpha$ for $n$-Si is observed with an increase in the doping level. A qualitative similarity is obtained between the changes in the thermoefficiency parameter for elastically deformed germanium and for silicon with an increase in the charge carrier concentration; although in the case of $n$-Ge the maximum $Z_{a}$ is much larger and is achieved at the higher doping level than in the case of $n$-Si. The results obtained can be useful in calculating various effects based on the theory of anisotropic scattering in a wide range of concentrations.
\end{abstract}

Keywords: germanium, silicon, doping level, elastic deformation, thermo-emf anisotropy, thermoefficiency parameter.

Received 07 June 2020; Accepted 15 September 2020

\section{Introduction}

In recent years, the task of increasing the efficiency of conversion of thermal energy into electrical energy has gained particular importance in connection with pressing problems caused by global climate change. Thermoelectric modules that directly convert thermal energy into electrical energy are gaining wider practical application and can play a key role in solving these problems [1-3].

Today, quite complex requirements are being put forward to modern electronic equipment materials, on the basis of which thermoelectric converters are made. These requirements apply equally to both the electronic and phonon subsystems $[4,5]$, since the dimensionless thermoelectric figure of merit $Z T=\alpha^{2} \sigma T / \chi$ is determined by the differential thermo-emf $\alpha$, electrical conductivity $\sigma$, and coefficient of thermal conductivity $\chi$ of the material. The magnitude of $Z$, having the dimension of the reciprocal temperature, which depends only on the physical properties of the material of the thermoelectric converter, is sometimes also called the thermoelectric figure of merit or the thermoefficiency parameter of the material.

Effective thermoelectric materials must simultaneously be characterized by high electrical conductivity and low thermal conductivity. It is believed that due to the high thermal conductivity, which increases with decreasing temperature, $n$-Ge and $n$-Si multi-valley semiconductors are not suitable for thermoelectric applications in the low temperature range 
$(T<300 \mathrm{~K})$, and for anisotropic thermoelements these semiconductors (as thermoelectrically-isotropic materials) are not applicable, in principle [6]. However, under conditions of strong uniaxial elastic deformation, the thermo-emf anisotropy appears in these crystals $[7,8]$.

The most important characteristics that determine the suitability of thermoelectrically anisotropic materials for their practical use are the thermo-emf anisotropy and the thermoefficiency parameter. The search of new methods for creating of the thermo-emf anisotropy is due to a number of circumstances: i) the number of thermoelectrically anisotropic materials is quite limited; ii) the value of the thermo-emf anisotropy of these materials in the range of room temperatures usually does not exceed $200-300 \mu \mathrm{V} / \mathrm{K}$ [9]; iii) in the case of a decrease in temperature, their anisotropy of thermo-emf decreases (and in some thermoelectrically anisotropic materials it even changes of sign $[9,10])$ and at 150 $200 \mathrm{~K}$ it is only a few tens of $\mu \mathrm{V} / \mathrm{K}$. Therefore, it was advisable to use the ability of directed elastic deformation to significantly increase the thermo-emf anisotropy in order to study the thermoelectric characteristics and find out the possibilities of using deformed $n$-Ge and $n$-Si crystals with different charge carrier concentration for thermoelectric needs.

The goal of this work was to establish the features of changes in the thermo-emf anisotropy and the thermoefficiency parameter of the uniaxially elastically deformed $n$-type germanium and silicon, depending on their doping level.

\section{Experiment}

The studies were carried out on $n$-Ge crystals with an electron concentration in the range of $11.8 \times 10^{13} \leq n_{e} \leq 2 \times 10^{18} \mathrm{~cm}^{-3}$ and on $n$-Si crystals in the range of the charge carrier concentrations of $1.9 \times 10^{13} \leq n_{e} \leq 2.6 \times 10^{16} \mathrm{~cm}^{-3}$. During the research, we used an installation that had been tested for many years [11] and which made it possible to smoothly set and remove the mechanical compressive stress in the range of $0 \leq X \leq 1.2 \mathrm{GPa}$ on the studied samples, which had the shape of parallelepipeds with dimensions $1 \times 1 \times 12 \mathrm{~mm}$. The uncertainty in determining the crystallographic orientation of the samples did not exceed 15'. Particular attention was paid to the fulfilment of the planeparallelism of the opposite faces, in particular for the end sides of the specimen, to which the load was applied, the deviation did not exceed 3'. To create a temperature gradient $\nabla T$, a gradient furnace with bifilar winding by a constantan wire, mounted on one of the sample ends, was used. To reduce the change in the average temperature of the sample, which is set by the ambient temperature, the temperature gradient on the sample did not exceed $5 \mathrm{deg} / \mathrm{cm}$. To minimize convection and transverse heat fluxes in the measuring cell with a sample, its volume was pumped out to $\sim 1.3 \mathrm{~Pa} \quad\left(10^{-2} \mathrm{~mm} \mathrm{Hg}\right)$. The experiments were conducted under conditions $\vec{X}\|\vec{j}, \nabla T\|[001]$ in the case of $n$-Si and under conditions $\vec{X}\|\vec{j}, \nabla T\|[111]$ in the case of $n-\mathrm{Ge}$ (where $\vec{j}$ is the current density that was passed through the sample when measuring the tensoresistance $\rho_{X} / \rho_{0}$ and the electrical conductivity $\sigma ; \nabla T$ is the temperature gradient that was used in the study of the thermo-emf $\alpha$ and the tenso-thermo-emf $\alpha_{X} / \alpha_{0}$ at $T=85 \mathrm{~K}$ ). The tensoresistance of the crystals was measured at $T=77 \mathrm{~K}$ using a current generator, which made it possible to carry out experiments with samples whose conductivity changed significantly. The temperature difference during the determination of the thermo-emf and the thermal conductivity was measured using copper-constantan thermocouples soldered to the lateral faces of the sample (at a distance of about $4 \mathrm{~mm}$ from each other). The thermo-emf was determined from the potential difference on the copper contacts of the thermocouples. For germanium samples, contacts and thermocouples were soldered using tin. In the case of silicon, the contacts were deposited using the $\mathrm{Au}+\mathrm{Si}$ eutectic (unsaturated $\mathrm{Si}$ ) at a temperature of $450{ }^{\circ} \mathrm{C}$, after which copper wires or copper-constantan thermocouples were soldered by tin to the created contacts. The contacts to the samples were tested for ohmicity at both room and nitrogen temperatures. Since the thermal conductivity under the conditions of the experiments was practically independent on the value of uniaxial elastic deformation, this coefficient was determined only for the case $X=0$. The electrical conductivity $\sigma$, mobility $\mu$, and charge carrier concentration $n_{e}$ were determined from measurements of the Hall effect and specific resistance. Measurement of the tenso-thermo-emf in saturation was carried out in the case of applying mechanical stresses of $X \geq 0.6 \mathrm{GPa}$, which ensured the complete migration of carriers from four (three) valleys for $n$-Si (for $n-\mathrm{Ge}$ ), ascending in the energy scale under the influence of deformation, into two (one) valleys that descend. The thermo-emf $\alpha_{0}$ was measured in the absence of deformation $(X=0)$. Differential preamplifiers were used to measure the potential difference on the electrical contacts of the test sample and thermocouples, the output signal of which was input into a computer using an interface board with analog-to-digital converters for further processing and analysis.

It should be noted that in the text of article, the index (0) denotes the magnitudes that were measured in the absence of the mechanical load on the sample (at $X=0$ ). The index $(\infty)$ denotes the magnitudes that were measured at such values of the mechanical stress $X \geq 0.6 \mathrm{GPa}$ that bring these values to saturation. Results and discussion

Under ordinary conditions, in the conduction band of undeformed $n$-Ge there are four equivalent isoenergetic ellipsoids, each of which contains $n_{0}=0.25 n_{e}$ electrons, where $n_{e}$ is the total charge carrier concentration in the conduction band of the crystal. Such germanium crystals are called the four-valley crystals (Fig. 1,a). When a mechanical compression stress $(\vec{X}\|\vec{j}\|[111])$ is applied to the $n$-Ge sample in the crystallographic direction [111], charge carriers are redistributed between the valleys that are displace (in the energy scale) in opposite directions (one valley goes down, and three rise up). Such a redistribution of carriers leads to an increase 

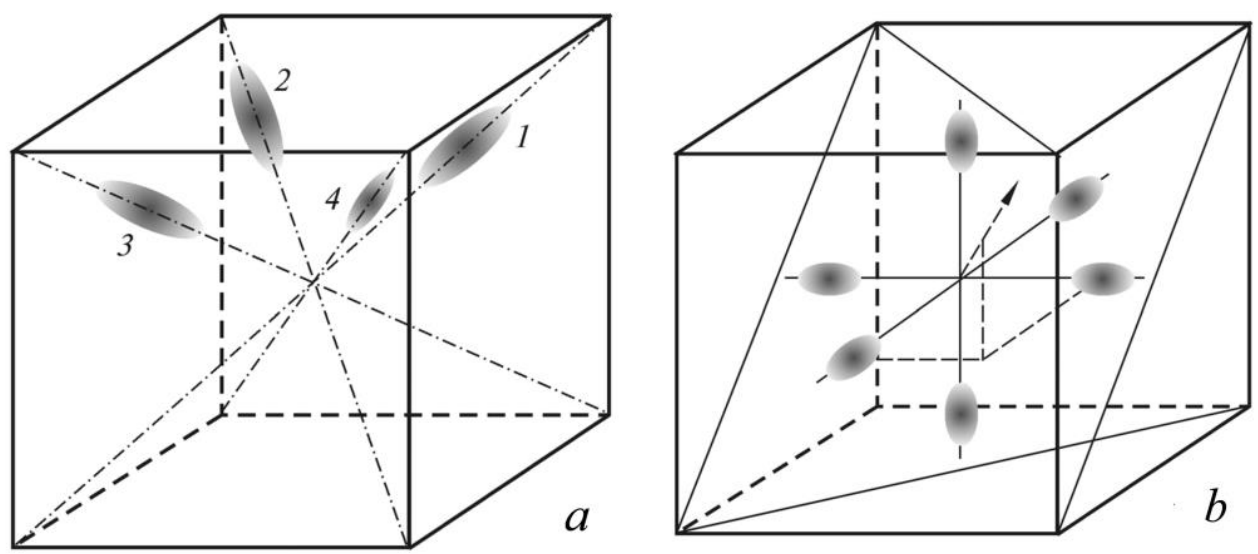

Fig. 1. The shape and arrangement of surfaces of constant energy: $a$ - for the four valleys of the conduction band, oriented along the symmetrically equivalent crystallographic directions $\langle 111\rangle$ in $n$-Ge; $b$ - for six valleys of the conduction band, oriented along directions $\langle 100\rangle$ in $n$-Si.

in resistivity with increasing pressure $X$. Under conditions of not too high temperatures $(T<90 \mathrm{~K})$ and when $X \geq 0.6 \mathrm{GPa}$ is applied to the sample, all free charge carriers pass on to one minimum of energy, which coincides with the direction of the deformation axis. Thus, the strong uniaxial elastic deformation transfers the $n$-Ge crystal from the four-valley to the single-valley state.

Under ordinary conditions, $n$-type silicon has six isoenergetic ellipsoids in the conduction band (Fig. 1,b). The application of strong $(X \geq 0.6 \mathrm{GPa})$ uniaxial elastic deformation in the crystallographic direction [001] transfers the $n$-Si crystal from the six- to two-valley state, which contributes to the emergence of the thermo-emf anisotropy $\Delta \alpha$ in the presence of the electron-phonon drag. In this case, the value of $\Delta \alpha$ can reach $20-30 \mathrm{mV} / \mathrm{K}$ at $T=85 \mathrm{~K}$, as the experiment showed. Such values of $\Delta \alpha$ are 100 - 200 times greater than the corresponding values of the thermo-emf anisotropy of the most common materials, which are characterized by natural thermoelectric anisotropy.

In the elastically uniaxially deformed crystals, when $X \geq 0.6 \mathrm{GPa}$, the electrical conductivity is described by the tensor:

$$
\hat{\sigma}=\left|\begin{array}{lll}
\sigma_{\perp} & 0 & 0 \\
0 & \sigma_{\perp} & 0 \\
0 & 0 & \sigma_{\|}
\end{array}\right|,
$$

where $\sigma_{\|}$and $\sigma_{\perp}$ are the electrical conductivity along and across the long axis of the isoenergetic ellipsoid, respectively. The thermo-emf tensor has a similar structure:

$$
\hat{\alpha}=\left|\begin{array}{lll}
\alpha_{\perp} & 0 & 0 \\
0 & \alpha_{\perp} & 0 \\
0 & 0 & \alpha_{\|}
\end{array}\right|,
$$

where $\alpha_{\|}$and $\alpha_{\perp}$ are the thermo-emf along and across the long axis of the isoenergetic ellipsoid, respectively.

In order for the thermo-emf anisotropy (the difference in the components of the thermo-emf along $\alpha_{\|}$ and across $\alpha_{\perp}$ the long axis of the isoenergetic ellipsoid) to be nonzero $\left(\Delta \alpha=\alpha_{\|}-\alpha_{\perp} \neq 0\right)$, it is sufficient that the inequality $m_{\|}-m_{\perp} \neq 0$ was realized, where $m_{\|}$and $m_{\perp}$ are the longitudinal and, accordingly, transverse effective masses of the electron in the isoenergetic ellipsoid. But even at $m_{\|} \neq m_{\perp}$, the thermo-emf anisotropy in silicon and germanium can appear (that is, $\Delta \alpha \neq 0$ ) only when the electron-phonon drag effect manifests itself.

A typical view of the dependences of tensoresistance $\rho_{X} / \rho_{0}=f(X)$ and tenso-thermo-emf $\alpha_{X} / \alpha_{0}=\varphi(X)$ obtained on $n$-Si and $n$-Ge crystals is shown in Fig. 2.

Thermoelements, depending on the principle of action, can be divided into ordinary (or isotropic)

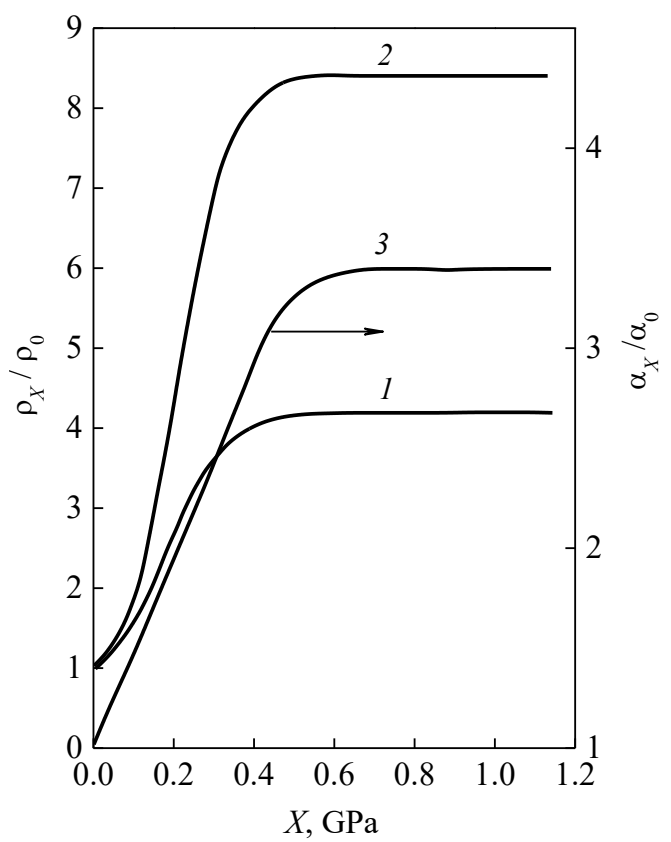

Fig. 2. Dependences of the longitudinal tensoresistance $\rho_{X} / \rho_{0}=f(X)$, measured at $T=77 \mathrm{~K}$ on crystals: $1-n-\mathrm{Si}$ $\left(\rho_{300 \mathrm{~K}} \cong 100 \mathrm{Ohm} \cdot \mathrm{cm} ; \quad \vec{X}\|\vec{j}\|[001]\right) ; 2-n$-Ge $\left(\rho_{300 \mathrm{~K}}=0.75 \mathrm{Ohm} \cdot \mathrm{cm} ; \vec{X}\|\vec{j}\|[111]\right)$; and the tensothermo-emf $\alpha_{X} / \alpha_{0}=\varphi(X)$, measured at $T=85 \mathrm{~K}: 3-$ $n-\mathrm{Si}$. 
and anisotropic (created on the basis of thermoelectrically anisotropic crystals). The thermoefficiency parameter $Z$ of the ordinary thermoelement is determined by the thermoelectric figure of merit of its branches [12]:

$$
Z=\left[\frac{\alpha_{1}+\alpha_{2}}{\alpha_{1} / \sqrt{Z_{1}}+\alpha_{2} / \sqrt{Z_{2}}}\right]^{2}
$$

herewith

$$
Z_{1}=\frac{\sigma_{1}}{\chi_{1}} \alpha_{1}^{2}, Z_{2}=\frac{\sigma_{2}}{\chi_{2}} \alpha_{2}^{2}
$$

$\left(Z_{i}, \alpha_{i}, \sigma_{i}\right.$ and $\chi_{i}$, where $i=1$ or 2 , are the thermoelectric figure of merit, thermo-emf, electrical conductivity and thermal conductivity of the corresponding branch of the thermoelement).

The thermoefficiency parameter of anisotropic thermoelements is determined mainly by the thermo-emf anisotropy:

$$
Z_{a}=\frac{\bar{\sigma}}{4 \bar{\chi}}(\Delta \alpha)^{2}
$$

where $\Delta \alpha=\alpha_{i i}-\alpha_{k k}$ is the thermo-emf anisotropy, which is determined by the difference in the principal values of the thermo-emf tensor $\left(\alpha_{i i}\right.$ and $\left.\alpha_{k k}\right)$; $\bar{\sigma}$ and $\bar{\chi}$ are the certain combinations of components of the tensors of electro- and thermal conductivity, which depend on the spatial distribution of vortex currents and heat fluxes. The view of these combinations depends both on the properties of the semiconductor, and on the design of the thermoelement based on it.

For an anisotropic thermoelement and some types of the vortex thermoelements [13], the combination of the components of the tensors of electro- and thermal conductivity included in (3) can be represented as:

$$
\bar{\sigma}=2 \frac{\sigma_{\|} \sigma_{\perp}}{\sigma_{\|}+\sigma_{\perp}}, \bar{\chi}=\frac{\chi_{\|}+\chi_{\perp}}{2},
$$

where $\sigma_{i}$ and $\chi_{i}(i=\|$ and $\perp)$ are the main values of the tensors of electro- and thermal conductivity. Then expression (3) will look like this:

$$
\mathrm{Z}_{a}=\frac{\sigma_{\|} \sigma_{\perp}}{\sigma_{\|}+\sigma_{\perp}} \frac{\left(\alpha_{\|}-\alpha_{\perp}\right)^{2}}{2 \chi} .
$$

The possibilities of increasing $Z_{a}$ can be seen from the expression (5). Thermoefficiency can be increased either by reducing the thermal conductivity, or by increasing the thermo-emf anisotropy $\Delta \alpha=\alpha_{\|}-\alpha_{\perp}$, or by increasing both $\sigma_{\|}$, and $\sigma_{\perp}$.

The values of $\sigma_{\|}=1 / \rho_{\|}=1 / \rho_{\infty}$ were measured directly on $n$-Ge and $n$-Si crystals, strongly deformed along the crystallographic directions, respectively [111] and [001]. Here $\rho_{\|}$is the resistivity along the long axis of the isoenergetic ellipsoid; $\rho_{\infty}$ is the resistivity at $X \geq 0.6 \mathrm{GPa}$ and $\vec{X}\|\vec{j}\|[111]$ (for $n$-Ge) and $\vec{X}\|\vec{j}\|[001]$ (for $n$-Si). The values of $\sigma_{\perp}$ were calculated by the formula:

$$
\sigma_{\perp}=\frac{1}{2}\left(3 \sigma_{0}-\sigma_{\|}\right),
$$

where $\sigma_{0}$ is the specific electrical conductivity of the crystal at $X=0$. The value of the thermo-emf anisotropy was calculated according to the procedure described in [13].

We take into account that the phonon $\alpha^{p h}$ and the electron (diffusion) $\alpha^{e}$ components of the thermo-emf are additive, and $\Delta \alpha$ in the region of impurity conductivity (i.e., under the conditions of one kind of carriers, even in the case of a strongly pronounced anisotropy of their effective mass) is determined only by the anisotropy of the phonon component $\alpha^{p h}=\alpha-\alpha^{e} \quad(\alpha$ is the experimentally measured thermo-emf).

The thermo-emf anisotropy in cubic crystals is determined by the difference in the components of the phonon constituent of the thermo-emf along and across the long axis of the isoenergetic ellipsoid, i.e. $\Delta \alpha=\alpha_{\|}-\alpha_{\perp} \equiv \alpha_{\|}^{p h}-\alpha_{\perp}^{p h}$. The electron component of the thermo-emf is calculated by the formula $\alpha^{e}=\frac{k}{e}\left[2+\ln \frac{2\left(2 \pi m^{*} k T\right)^{3 / 2}}{n_{e} h^{3}}\right]$ [7], where $n_{e}$ is the charge carrier concentration; $e$ is the electron charge; $k$ is the Boltzmann constant; $T$ is the temperature; $h$ is Planck's constant; $m^{*}=N^{2 / 3} \sqrt[3]{m_{\|} m_{\perp}^{2}}$ is the effective mass of the density of states; $N$ is the number of isoenergetic ellipsoids: in the case of $n-\mathrm{Ge}$ $N=\left\{\begin{array}{l}4 \text { at } X=0 \\ 1 \text { at } X \geq 0.6 \mathrm{GPa}, \quad \vec{X} \|[111]\end{array}\right.$, in the case of $n-$ Si $N=\left\{\begin{array}{ll}6 & \text { at } \quad X=0 \\ 2 & \text { at } \quad X \geq 0.6 \mathrm{GPa}, \quad \vec{X} \|[001]\end{array}\right.$.

The thermo-emf anisotropy $\Delta \alpha$ was determined from the results of the measurements of thermo-emf, tensothermo-emf, and tensoresistance in accordance with the formula

$$
\Delta \alpha=\left(\alpha_{\infty}^{p h}-\alpha_{0}^{p h}\right)\left(1+\frac{1}{2 K}\right)
$$

where $K=\frac{\mu_{\perp}}{\mu_{\|}}=\frac{3}{2} \frac{\rho_{\infty}}{\rho_{0}}-\frac{1}{2}$ is the anisotropy parameter of mobility; $\rho_{0}$ and $\rho_{\infty}$ are the resistivity of the undeformed crystal (at $X=0$ ) and in saturation (under the conditions of $X \geq 0.6 \mathrm{GPa}, \vec{X}\|\vec{j}\|$ [001] for $n$-Si and at $X \geq 0.6 \mathrm{GPa}, \quad \vec{X}\|\vec{j}\|[111]$ for $n-\mathrm{Ge}) ; \quad \alpha_{0}^{p h}=\alpha_{0}-\alpha^{e}$ and $\alpha_{\infty}^{p h}=\alpha_{\infty}-\alpha^{e}$ are the phonon components of the thermo-emf and tenso-thermo-emf in the undeformed and deformed samples, respectively.

The values of $Z_{0}$ and $Z_{\infty}$ were calculated using expressions of type (2), and the value of $Z_{a}$ was calculated using expression (5). The main characteristics of the germanium and silicon studied samples are shown in Figs. 3-7, where $\alpha_{0}, Z_{0}$ and $\alpha_{\infty}, Z_{\infty}$ are the values of thermo-emf and thermoelectric figure of merit of undeformed (indicated by index 0 ) and strongly deformed crystals $(\infty) ; \Delta \alpha$ and $Z_{a}$ are the thermo-emf anisotropy and the thermoefficiency parameter of the anisotropic thermoelement based on the strongly deformed $n$-Ge and $n$-Si.

The thermal conductivity of silicon at $85 \mathrm{~K}$ is about 


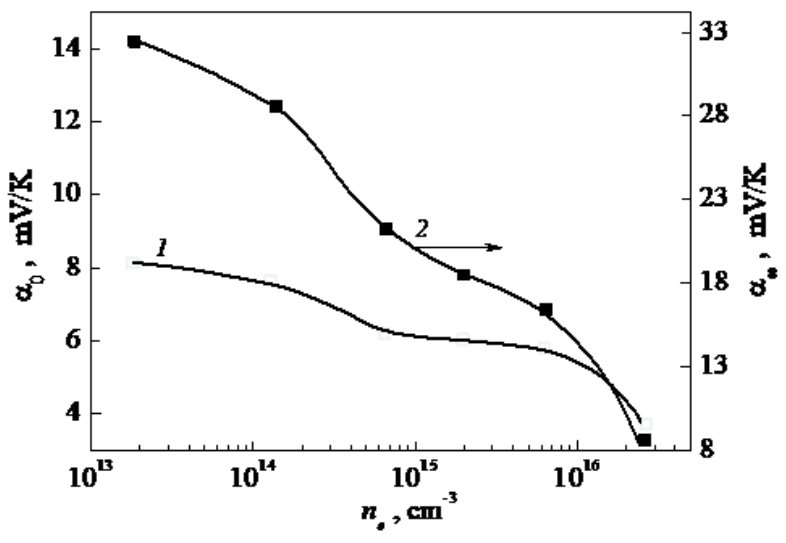

Fig. 3. Dependences of the thermo-emf $\alpha_{0}=\alpha_{0}\left(n_{e}\right)$ (1) and the tenso-thermo-emf $\alpha_{\infty}=\alpha_{\infty}\left(n_{e}\right)$ (2) for $n$-Si at $T=85 \mathrm{~K}$.

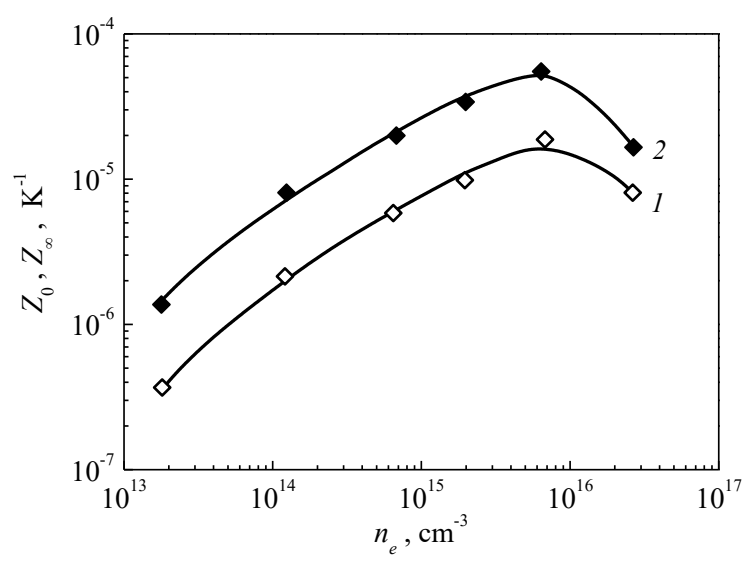

Fig. 4. Dependences at $T=85 \mathrm{~K}$ of the thermoelectric figure of merit on the doping level of $n$-Si crystals in the absence $Z_{0}(1)$ and in the presence $Z_{\infty}(2)$ of strong uniaxial elastic deformation.

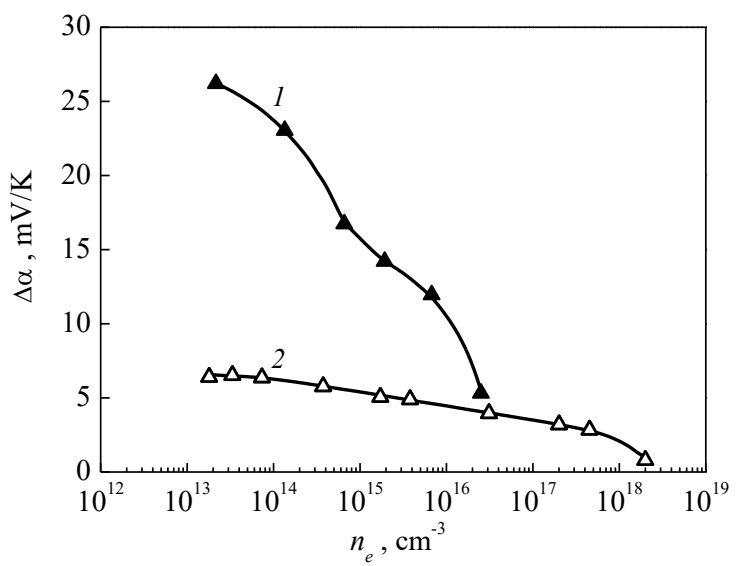

Fig. 5. Dependences of the thermo-emf anisotropy $\Delta \alpha=f\left(n_{e}\right)$ for $n$-Si $(\vec{X}\|\vec{j}\|[001])$ (1) and $n$-Ge ( $\vec{X}\|\vec{j}\|[111])(2)$ at $T=85 \mathrm{~K}$.

$11.5 \mathrm{~W} / \mathrm{cm} \mathrm{K}$ [15]. In the case of increasing the doping level to the maximum value (of the studied ones), a slight decrease in thermal conductivity was observed due to some increase in the phonon scattering efficiency on impurities, which could only positively affect the values of $Z$ and $Z_{a}$.

Fig. 3 shows that the dependence $\alpha_{0}\left(n_{e}\right)$ (curve 1 ) in the range of the charge carrier concentrations $6 \times 10^{14} \leq n_{e} \leq 6 \times 10^{15} \mathrm{~cm}^{-3}$ has a weakly pronounced "plateau" due to the combined manifestation of the ordinary mechanism of the thermo-emf formation with the effect of electron-phonon drag. In the studied range of $n_{e}$ concentrations, in the case of applying a strong deforming force $X \geq 0.6 \mathrm{GPa}$ to $n$-Si, both the tensothermo-emf $\alpha_{\infty}$ (Fig. 3, curve 2) and the figure of merit $Z_{\infty}$ (Fig. 4, curve 2) increase significantly, in comparison with the thermo-emf $\alpha_{0}$ and the figure of merit $Z_{0}$ in the absence of mechanical load (at $X=0$ ). The fall-off in the values of $Z_{0}, Z_{\infty}$ (Fig. 4) and $Z_{a}$ (Fig. 6, curve 1) with an increase in the carrier concentration $n_{e}$ above $7 \times 10^{15} \mathrm{~cm}^{-3}$ is associated with a sharp decrease in the thermo-emf $\alpha$ in the range of $n_{e}>7 \times 10^{15} \mathrm{~cm}^{-3}$ (see Fig. 3).

Comparison of curves 1 and 2 in Fig. 5 shows that in the case of a low doping level, the thermo-emf anisotropy of uniaxially elastically deformed $n$-Si crystals exceeds the anisotropy of $n$-Ge crystals more than 4 times. However, with an increase in the doping level, a faster decrease of $\Delta \alpha$ is observed for silicon crystals than for germanium, and when the charge carrier concentration is of the order of $3 \times 10^{16} \mathrm{~cm}^{-3}$, the values of the thermo-emf anisotropy for both crystals almost coincides.

The thermo-emf anisotropy that occurs in the region of electron-phonon drag in the case of elastic deformation of $n$-Si crystals ( $\vec{X}\|\nabla T\|[001])$ and determines the sensitivity of the anisotropic thermoelement exceeds $\Delta \alpha$ of the traditional thermoelectrically anisotropic materials by about twothree orders of magnitude (see [9], p. 278). The analysis of the results obtained (see Fig. 6) showed that anisotropic thermoelements can be created based on the strongly uniaxially elastically deformed $n$-Si crystals at $85 \mathrm{~K}$. Such thermoelements will have a sensitivity of about two-three orders of magnitude higher, and the coefficient of efficiency is not worse than in thermoelements created on the basis of other known thermoelectrically anisotropic materials.

As follows from Fig. 5 (curve 2), the thermo-emf anisotropy of uniaxially deformed $n$-Ge with increasing the concentration decreases from $6400 \mu \mathrm{V} / \mathrm{K}$ at $n_{e}=1.8 \times 10^{13} \mathrm{~cm}^{-3}$ to $800 \mu \mathrm{V} / \mathrm{K}$ at $n_{e}=2 \times 10^{18} \mathrm{c}^{-3}$. However, despite the fact that $\Delta \alpha$ monotonically decreases (with an increase in the doping level of crystals) and $Z_{a} \sim(\Delta \alpha)^{2}$, the thermoefficiency parameter $Z_{a}$ with increasing the concentration $n_{e}$ in the studied $n$-Ge samples (approximately to $\left.n_{e} \approx(2-3) \times 10^{17} \mathrm{~cm}^{-3}\right)$ grows (Fig. 6, curve 2). Such specificity of the change in $Z_{a}$ is related to the fact that in the studied concentration range, the specific electrical conductivity of crystals increases by about $10^{4}$ times at the thermal conductivity, which decreases simultaneously. A further decrease in $Z_{a}$ with an increase in $n_{e}$ above $4.6 \times 10^{17} \mathrm{~cm}^{-3}$ is associated with a sharp fall-off in the thermo-emf anisotropy in the region of such high concentrations.

From the obtained results it follows that the 
uniaxially elastically deformed $n$-Ge at $T=85 \mathrm{~K}$ has sufficiently high values of the thermo-emf anisotropy $\Delta \alpha$ and, probably, the highest thermoefficiency parameter $Z_{a}$ from among the known thermoelectrically anisotropic materials [9].

A feature of the change in curves 1 and 2 (Fig. 6) is the passage through a pronounced maximum with a subsequent decrease in the thermoefficiency parameter with increasing the charge carrier concentration. Fig. 6 shows the qualitative similarity of the shape of the dependences $Z_{a}=Z_{a}\left(n_{e}\right)$ for the uniaxially elastically deformed $n$-Si and $n$-Ge crystals (curves $l$ and 2). However, the maximal value of the thermoefficiency parameter for germanium $Z_{a \text { max }}^{\mathrm{Ge}}=7.9 \times 10^{-5} \mathrm{~K}^{-1}$ (curve 2) is 6.5 times higher than the maximal value of $Z_{a}$ for silicon $Z_{a \max }^{\mathrm{Si}}=1.22 \times 10^{-5} \mathrm{~K}^{-1}$ (curve 1). Herewith, the maximum $Z_{a}$ for $n$-Ge is observed at a significantly higher doping level $\left(n_{e} \approx 2 \times 10^{17} \mathrm{~cm}^{-3}\right)$, than for $n$-Si $\left(n_{e} \approx 6.8 \times 10^{15} \mathrm{~cm}^{-3}\right)$.

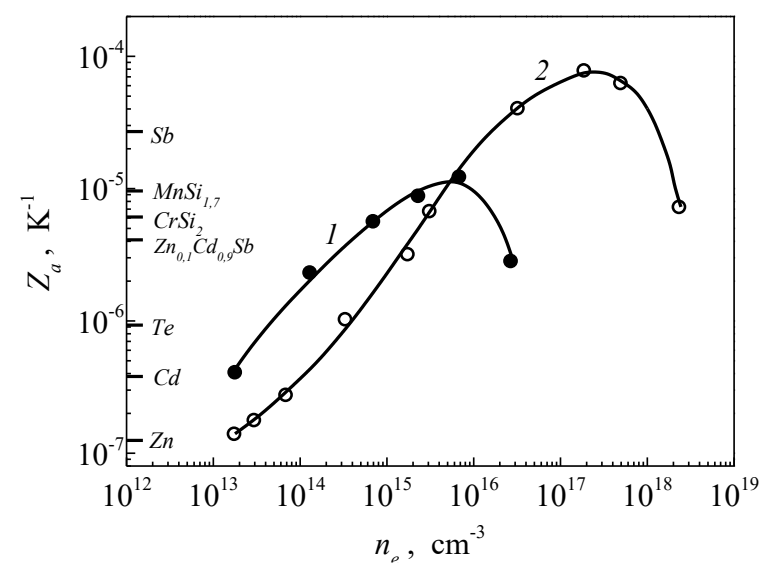

Fig. 6. Dependences $\mathrm{Z}_{a}=f\left(n_{e}\right)$ at $T=85 \mathrm{~K}$ for $n-\mathrm{Si}$ ( $\vec{X}\|\vec{j}\|$ [001]) (1) and $n$-Ge ( $\vec{X}\|\vec{j}\|$ [111]) (2). The marks on the scale are $Z_{a}$ for known thermoelectrically anisotropic materials (see [9], p. 278).

The values of $Z_{a}$ of the most used thermoelectrically anisotropic materials were marked (for comparison) on the $y$-axis in Fig. 6. It was established that, despite the high thermal conductivity, which grows in $n$-Si with decreasing temperature, these crystals (in the elastically deformed state) can have a thermoefficiency parameter comparable with the similar parameter of the most used thermoelectrically anisotropic materials.

To solve a number of applied problems (in particular, when creating the anisotropic thermoelements based on the uniaxially elastically deformed $n$-Si, operating in a wide temperature range), it is necessary to have the information about the temperature dependences of thermoelectric characteristics. The temperature dependencies of the thermo-emf anisotropy (curve 1) and the thermoefficiency parameter (curve 2) were presented in Fig. 7 for $n$-Si crystals $\left(n_{e}=1.75 \times 10^{14} \mathrm{~cm}^{-3}\right)$. The dependences of the known thermoelectrically anisotropic materials $\mathrm{Zn}_{x} \mathrm{Cd}_{1-x} \mathrm{Sb}$ [10] and $\mathrm{CdSb}$ [9] were also exhibited for comparison in the inset. In these materials, at the temperatures above the room, the thermo-emf anisotropy arises due to the presence of several kinds of carriers (at one scattering mechanism) [8]. At low temperatures, the thermo-emf anisotropy is due to the presence of several scattering mechanisms for $\mathrm{CdSb}$ or the effect of the drag of electrons (with anisotropic $\mathrm{m}^{*}$ ) by phonons for $\mathrm{Zn}_{x} \mathrm{Cd}_{1-x} \mathrm{Sb}$. In the elastically deformed $n$-Si in the entire temperature range studied (from 80 to $360 \mathrm{~K})$, the thermo-emf anisotropy is caused by the action of only one mechanism, associated with the effect of the drag of electrons (with anisotropic effective mass) by phonons. With decreasing temperature, the determinative role of the effect of electron-phonon drag ensures an increase in the thermo-emf anisotropy in $n$-Si.

Fig. 7 shows that in the entire temperature range studied, the thermo-emf anisotropy, which determines the sensitivity of the anisotropic thermoelements to the temperature gradient of the elastically deformed silicon, significantly exceeds $\Delta \alpha$ of the known thermoelectrically anisotropic materials. Thus, in the low temperature range the thermo-emf anisotropy of the deformed silicon is more than two orders of magnitude higher than the anisotropy of the ordinary materials of the highest class in the absence of deformation $(0.2 \mathrm{mV} / \mathrm{K})$ and it reaches of values of the order of $24 \mathrm{mV} / \mathrm{K}$. And even at high temperatures, the thermo-emf anisotropy of the deformed silicon is more than three times higher than the maximal values of $\Delta \alpha$ of the best thermoelectric materials in the absence of deformation (Fig. 7, curves 1 and 2 in the inset).

The dependence $Z_{a}=Z_{a}(T)$ (Fig. 7, curve 2) was calculated by formula (5) using the results of

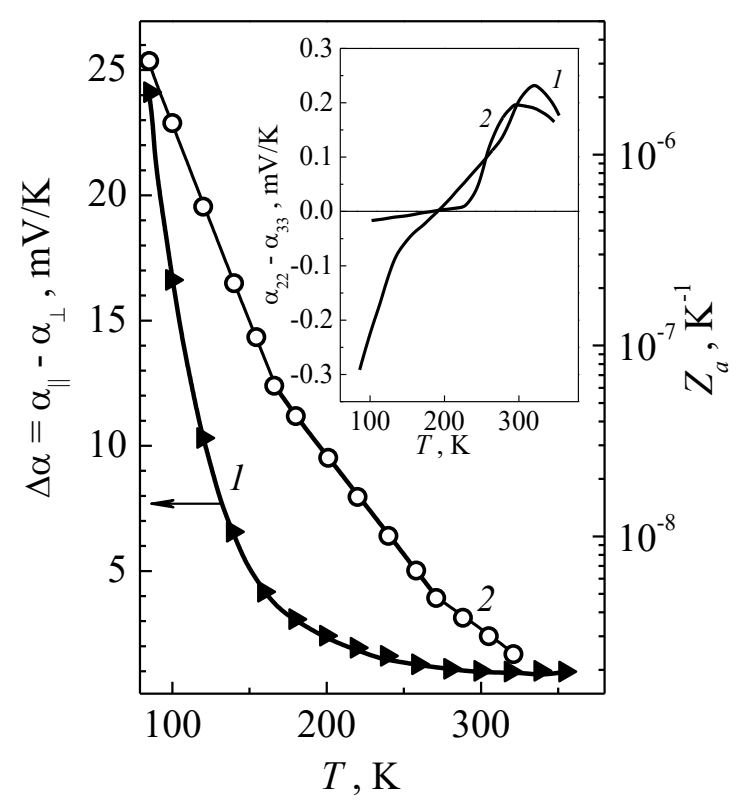

Fig. 7. Dependences of the thermo-emf anisotropy $\Delta \alpha=\alpha_{\|}-\alpha_{\perp}(1)$ and the thermoefficiency parameter $Z_{a}$ (2) on the temperature for the uniaxially elastically deformed $n$-Si $\left(n_{e}=1.75 \times 10^{14} \mathrm{~cm}^{-3} ; \quad \vec{X}\|\vec{j}\|[001]\right)$. The inset shows the dependences of the thermo-emf anisotropy $\Delta \alpha=\alpha_{22}-\alpha_{33}$ on the temperature for thermoelectrically anisotropic materials $\mathrm{Zn}_{x} \mathrm{Cd}_{1-x} \mathrm{Sb}$ (1) and $\mathrm{CdSb}(2)[9,10]$. 
measurements of the temperature dependences of the corresponding parameters. The analysis of the obtained results showed that the strongly deformed $n$-Si is a good low-temperature thermoelectrically anisotropic material. In the temperature range studied, it has a sufficiently high thermoefficiency parameter $Z_{a}$, which increases significantly with decreasing temperature (due to an increase in $\Delta \alpha$ (Fig. 7, curve 1) and electrical conductivity (from $1.42 \times 10^{-2} \mathrm{Ohm}^{-1} \cdot \mathrm{cm}^{-1}$ at $320 \mathrm{~K}$ to $1.11 \times 10^{-1} \mathrm{Ohm}^{-1} \cdot \mathrm{cm}^{-1}$ at $85 \mathrm{~K}$, as the experiment showed)).

Since the thermoelectric characteristics of the most used materials deteriorate significantly with decreasing temperature [9], it can be concluded that the uniaxially elastically deformed germanium (one-valley) and silicon (two-valley) are unique thermoelectrically anisotropic materials that characterized by the high values of the thermo-emf anisotropy $\Delta \alpha$ and the quite acceptable values of the thermoefficiency parameter $Z_{a}$.

\section{Conclusions}

As a result of the carried out experiments, the following conclusions can be made.

1. Peculiarities of changes in the thermo-emf anisotropy $\Delta \alpha$ and the thermoefficiency parameter $Z_{a}$ for uniaxially elastically deformed (at $X \geq 0.6 \mathrm{GPa}$ ) $n$-Si and $n$-Ge, depending on their doping level, were established.

2. It was revealed that in the case of a low doping level $\left(n_{e} \approx 1.9 \times 10^{13} \mathrm{~cm}^{-3}\right)$, the thermo-emf anisotropy of the deformed $n$-Si crystals exceeds of the $\Delta \alpha$ value for $n$-Ge crystals more than 4 times.

3. It was shown that with an increase in the doping level, the $\Delta \alpha$ decreases rapidly for $n$-Si, and when the charge carrier concentration is of the order of $3 \times 10^{16} \mathrm{~cm}^{-3}$, the values of the thermo-emf anisotropy for $n$-Si and $n$-Ge almost coincide.

4. A qualitative similarity was obtained between the changes in the thermoefficiency parameter $Z_{a}=Z_{a}\left(n_{e}\right)$ for uniaxially elastically deformed germanium and silicon with an increase in the charge carrier concentration, although in the case of $n$-Ge the maximum $\mathrm{Z}_{a}$ is much larger (6.5 times) and is reached at the doping level $\left(n_{e} \approx 2 \times 10^{17} \mathrm{~cm}^{-3}\right)$, which exceeds by more than an order of magnitude the corresponding doping level for $n$-Si $\left(n_{e} \approx 6.8 \times 10^{15} \mathrm{~cm}^{-3}\right)$.

5. It was shown that uniaxially elastically deformed $n$-Ge at $85 \mathrm{~K}$ has enough high values of thermo-emf anisotropy, and its thermoefficiency parameter exceeds $Z_{a}$ of most known thermoelectrically anisotropic materials.

Gaidar G.P. - Doctor of Physical and Mathematical Sciences, Senior Researcher, Head of the Department of Radiation Physics.

[1] X. Zhang, Li-D. Zhao, J. Materiomics 1(2), 92 (2015) (https://doi.org/10.1016/j.jmat.2015.01.001).

[2] T.C. Harman, P.J. Taylor, M.P. Walsh, $\quad$ B.E. LaForge, Science 297(5590), 2229 (2002) (DOI: 10.1126/science.1072886).

[3] T.M. Tritt, M.A. Subramanian, MRS Bull. 31(3), 188 (2006) (https://doi.org/10.1557/mrs2006.44).

[4] Z.-G. Chen, G. Han, L. Yang, L. Cheng, J. Zou, Prog. Nat. Sci.-Mater. 22(6), 535 (2012) (https://doi.org/10.1016/j.pnsc.2012.11.011).

[5] M. Mori, Y. Shimotsuma, T. Sei, M. Sakakura, K. Miura, H. Udono, Phys. Status Solidi A 212(4), 715 (2015) (https://doi.org/10.1002/pssa.201431777).

[6] A.A. Snarskii, A.M. Palti, A.A. Ascheulov, Fiz. Tehn. Poluprov. 31(11), 1281 (1997) (http://journals.ioffe.ru/articles/viewPDF/32975).

[7] P.I. Baranskii, G.P. Gaidar, J. Thermoelectricity (2), 29 (2012) (http://nbuv.gov.ua/UJRN/TE_2012_2_4).

[8] G.P. Gaidar, Phys. Chem. Solid St. 14(1), 7 (2013) (http://page.if.ua/uploads/pcss/vol14/1401-01.pdf).

[9] L.I. Anatychuk, Thermoelements and Thermoelectric Devices. Hand-book (Naukova Dumka, Kyiv, 1979).

[10] I.S. Buda, I.M. Pilat, K.D. Soliychuk, Fiz. Tehn. Poluprov. 7(10), 1925 (1973).

[11] P.I. Baranskii, A.E. Belyaev, G.P. Gaidar, Kinetic effects in multi-valley semiconductors (Naukova Dumka, Kyiv, 2019).

[12] A.F. Ioffe, Semiconductor Thermoelements (Izd-vo AN SSSR, Moscow-Leningrad, 1960).

[13] L.I. Anatychuk, L.N. Vikhor, Thermoelectricity. Vol. IV. Functional-Gradient Thermoelectric Materials (Institute of Thermoelectricity, Kyiv-Chernivtsi, 2012).

[14] G.P. Gaidar, P.I. Baranskii, Physica B 441, 80 (2014) (http://dx.doi.org/10.1016/j.physb.2014.02.011).

[15] P.I. Baranskii, V.P. Klochkov, I.V. Potyikevich, Semiconductor Electronics. Hand-book (Naukova Dumka, Kyiv, 1975). 


\title{
Г.П. Гайдар
}

\section{Анізотропія термоерс і параметр термоефективності пружно деформованих германію і кремнію різних рівнів легування}

\author{
Інститут ядерних досліджень НАН Украӥни, Київ, Украӥна, gaydar@kinr.kiev.иа
}

Найважливішими характеристиками, що визначають придатність термоелектричноанізотропних матеріалів до їхнього практичного використання, $\epsilon$ анізотропія термоерс $\Delta \alpha \mathrm{i}$ параметр термоефективності $Z_{a}$. Перша з цих характеристик визначає напругу, що генерується анізотропним термоелементом, а друга - його коефіцієнт корисної дії. У роботі досліджено особливості змін анізотропії термоерс і параметра термоефективності пружно деформованих кристалів германію і кремнію при $85 \mathrm{~K}$ залежно від рівня їх легування. Виявлено, що в разі низького рівня легування анізотропія термоерс деформованих кристалів $n$-Si перевищує $\Delta \alpha$ кристалів $n$-Ge більше, ніж у 4 рази. Показано, що зі зростанням рівня легування спостерігається стрімкий спад $\Delta \alpha$ для $n$-Si. Одержано якісну подібність змін параметра термоефективності для пружно деформованих германію і кремнію з підвищенням концентрації носіїв заряду, хоча у випадку $n$-Ge максимум $Z_{a}$ значно більший і досягається при вищому рівні легування, ніж у випадку $n$-Si. Одержані результати можуть бути корисними при розрахунках різних ефектів на основі теорії анізотропного розсіювання в широкому інтервалі концентрацій.

Ключові слова: германій, кремній, рівень легування, пружна деформація, анізотропія термоерс, параметр термоефективності. 